\title{
Novas espécies e nota sobre Lamiinae (Coleoptera, Cerambycidae) neotropicais da coleção Arriagada, Santiago, Chile
}

\author{
Ubirajara R. Martins ${ }^{1,3}$ \\ Maria Helena M. Galileo ${ }^{2,3}$
}

\begin{abstract}
New species and note on Neotropical Lamiinae (Coleoptera, Cerambycidae) of the Arriagada's collection, Santiago, Chile. New species described: Acanthoderini - Acanthoderes (Psapharochrus) piraiuba sp. nov. from Argentina (San Luis); Acanthoderes (Acanthoderes) uyapensis sp. nov. from Bolivia (La Paz); Dufauxia simplex sp. nov. from Paraguay (Caazapá); Aerenicini - Antodice quadrimaculata sp. nov. from Paraguay (Caazapá); Calliini - Drycothaea maculata sp. nov. from Bolivia (La Paz); Falsamblesthiini - Obereoides antennatus sp. nov. from Bolívia (La Paz). Color variation of Phoebe spegazzinii Bruch, 1908 is discussed.
\end{abstract}

KeYwords. Arriagada's collection; Cerambycidae; Lamiinae; Neotropical; taxonomy.

\section{INTRODUÇÃO}

Recebemos para estudo parte dos Cerambycidae da coleção Gerardo Arriagada, de Santiago, Chile (GASC), que reúne, principalmente, exemplares da Bolívia, Paraguai e Argentina. Nesta contribuição apresentamos espécies novas em Acanthoderini, Aerenicini, Callidiini e Falsamblesthiini. Acrescentamos nota sobre a variabilidade no padrão do colorido de Phoebe spegazzinii Bruch, 1908 que está arrolada para a Argentina e é assinalada agora para a Bolívia e o Paraguai.

O material estudado encontra-se depositado no Museu de Ciências Naturais, Fundação Zoobotânica do Rio Grande do Sul, Porto Alegre (MCNZ) e no Museu de Zoologia, Universidade de São Paulo, São Paulo (MZSP).

Acanthoderini

Acanthoderes (Psapharochrus) piraiuba sp. nov.

(Fig. 1)

Etimologia. Tupi: pira = corpo; iuba = amarelo; alusivo ao colorido da pubescência.

Fêmea. Tegumento avermelhado em todo corpo, mas pouco mais escuro no pronoto. Cabeça revestida por pubescência amarelada. Fronte com pontos esparsos, mais ou menos visíveis sob a pubescência. Vértice com poucos pontos entre os tubérculos anteníferos. Lobos oculares ligados por única fileira de omatídios. Lobos oculares superiores com oito fileiras de omatídios, tão distantes entre si quanto mais do que o quíntuplo da largura de um lobo. Lobos oculares inferiores com o mesmo comprimento da área malar. Face ventral da cabeça glabra, lisa e brilhante.

Antenas alcançam aproximadamente o quarto apical dos élitros. Escapo revestido por pubescência amarelada; tão longo quanto o antenômero IV. Flagelômeros recobertos por pubescência amarelada e levemente escurecidos nos ápices. Antenômero III com 4-5 pêlos internos (20x). Antenômero V escurecido na metade apical. Antenômeros seguintes com comprimentos gradualmente decrescentes.

Lados do protórax com espinho desenvolvido. Pronoto com duas gibosidades grandes, situadas mais próximas da margem anterior e uma gibosidade centro-posterior, longitudinal e menos elevada. Pontuação pronotal abundante, profunda, não acobertada pela pubescência. Partes laterais do protórax com pontuação e pubescência semelhantes às do pronoto. Processo prosternal regularmente curvo, sem tubérculos. Processo mesosternal gradualmente elevado, sem tubérculos. Mesepisternos com cinco pontos próximos, perto do meio.

1. Museu de Zoologia, Universidade de São Paulo. Caixa Postal 42494, 04218-970 São Paulo-SP, Brasil.

2. Museu de Ciências Naturais, Fundação Zoobotânica do Rio Grande do Sul. Caixa Postal 1188, 90001-970 Porto Alegre-RS, Brasil.

3. Bolsista do CNPq. 
Metepisternos e lados do metasterno com alguns pontos.

Pubescência amarelada dos élitros densa perto da base e organizada em fileiras longitudinais nas costas; os pêlos $(25 \mathrm{x})$ dirigidos para a parte posterior. Região dorsal próxima do escutelo aplanada com pontos moderadamente densos, semelhantes aos do pronoto. Extremidades elitrais obliquamente truncadas.

Fêmures e tíbias pubescentes, sem pontos contrastantes. Tarsômeros com tegumento unicolor e pubescência amarelada, uniforme. Face ventral revestida por pubescência amarelada.

Dimensões, em mm. Comprimento total, 15,3; comprimento do protórax, 3,0; maior largura do protórax, 5,6; comprimento do élitro, 11,3; largura umeral, 6,7; antenômero III, comprimento, 2,6; antenômero IV, comprimento, 2,0; antenômero V, comprimento, 1,8 .

Holótipo fêmea procedente da Argentina, San Luis: Desaguadero, coletado em 20.II.2000 por G. Arriagada (MZSP).

Discussão. Espécies de Acanthoderes, s. lat., com pubescência corporal uniforme são raras e talvez uma exceção poderia ser Acanthoderes (Psapharochrus) nigricans Lameere, 1885. Acanthoderes (P.) piraiuba sp. nov. difere obviamente de $A$. (P.) nigricans pelo colorido corporal que, nesta espécie, é preto.

\section{Acanthoderes (Acanthoderes) uyapensis sp. nov.}

(Fig. 2)

Macho. Fronte com tegumento avermelhado, fina e esparsamente pontuada, restante da cabeça com tegumento preto. Olhos divididos. Lobos oculares superiores com cerca de dez fileiras de omatídios, tão distantes entre si quanto o dobro da largura de um lobo. Lobos oculares inferiores mais curtos que a área malar. Vértice com alguns pontos. Antenas mais longas que o corpo. Escapo preto, liso, com alguns pêlos brancos, esparsos. Antenômero III um terço mais longo que o escapo, avermelhado e escurecido no ápice, com anel branco estreitíssimo. Antenômero IV castanho com pubescência branca no terço basal e enegrecido no ápice; comprimento igual a um terço do III. Antenômeros seguintes acastanhados com anel basal de pubescência branca e com comprimentos decrescentes.

Protórax avermelhado mais escurecido nos tubérculos. Lados do protórax com tubérculo desenvolvido. Pronoto com quatro elevações: duas látero-anteriores, longitudinais e convergentes para a frente; uma centro-basal menor, menos projetada e uma perto da margem anterior, muito pequena, entre as látero-anteriores. Pubescência da região central do pronoto mais clara que a das partes laterais. Pontuação pronotal muito esparsa, os pontos pequenos, menos os da fileira adiante da margem posterior. Partes laterais do protórax com pubescência esbranquiçada na metade inferior. Processo prosternal curvo, sem tubérculos. Processo mesosternal aplanado e com um tubérculo a cada lado. Metasterno preto com escassos pêlos brancos, principalmente nos lados. Urosternitos pretos com manchas pequenas de pubescência esbranquiçada.

Élitros com tegumento predominantemente avermelhado, revestido por pubescência fina e esbranquiçada entremeada por manchas de tegumento preto, das quais as mais conspícuas são: um conjunto de manchas que constitui uma faixa quebrada ao nível do quarto anterior; em cada élitro uma faixa dorsal e oblíqua em sentido descendente da margem para a sutura e situada para trás do meio; pequena mancha dorsal, próxima da sutura, no quinto apical; perímetro dos pontos, principalmente na região central e ao longo da sutura. Pubescência branca em cada élitro: duas manchas muito pequenas nos lados do escutelo; mancha pequena, sutural, ao nível do terço anterior; manchas pequenas, numa faixa transversal situada no quarto apical. Crista centro-basal marcada e encimada por fileira de pequenos tubérculos. Pontuação da metade anterior esparsa; em cada ponto implanta-se um pêlo branco $(32 \mathrm{x})$. Extremidades elitrais transversalmente truncadas com curta projeção no lado externo.

Fêmures avermelhados, escurecidos no ápice e providos de pilosidade branca e esparsa. Protíbias avermelhadas, com anel central de pilosidade branca e esparsa e alargadas para o ápice. Meso- e metatíbias avermelhadas com anel central de pubescência branca pouco concentrada. Protarsos com os dois primeiros artículos pretos e os dois últimos revestidos por pilosidade branca. Meso- e metatarsos revestidos por pilosidade branca.

Dimensões, em mm. Comprimento total, 14,7; comprimento do protórax, 3,0; maior largura do protórax, 5,2; comprimento do élitro,10,7; largura umeral, 6,4.

Holótipo macho procedente da Bolívia, La Paz: Uyapi (Guanay), coletado em 15-25.XI.1995, sem nome do coletor (MZSP).

Discussão. Espécies da Bolivia do gênero Acanthoderes, s. lat., foram principalmente descritas e figuradas porTIPPMANN (1960, fig. 24 a-f). Acanthoderes (A.) zischkai é a espécie que mais se assemelha, pelo padrão do colorido, a $A$. (A.) uyapensis sp. nov. mas, mesmo assim, tem padrão de colorido completamente diverso.

Em $A$. (A.) rufofemorata Aurivillius, 1926, também conhecida da Bolívia, segundo a descrição, os élitros são providos de várias manchas brancas, as antenas dos machos são mais curtas do que o corpo e o antenômero X é piloso inferiormente. $\operatorname{Em} A$. (A.) uyapensis, os élitros (Fig. 2) apresentam escassas manchas brancas, as antenas dos machos são nitidamente mais longas que o corpo e o antenômero $\mathrm{X}$ não tem pêlos.

\section{Dufauxia simplex sp. nov.} (Fig. 6)

Macho. Fronte preta, revestida por pubescência variegada, mais escura no centro. Lobos oculares superiores com cinco fileiras de omatídios, pouco mais afastados entre si do que a largura de um lobo. Lobos oculares inferiores tão longos quanto a área malar. Antenas com mais do dobro do comprimento do corpo, atingem as pontas dos élitros, aproximadamente, no meio 
do antenômero VI. Escapo revestido por pubescência predominantemente esbranquiçada com anel preto perto da base; comprimento menor que a metade do antenômero III. Flagelômeros apicais escurecidos para as extremidades. Flagelômeros basais com tegumento avermelhado revestidos por pubescência esbranquiçada e escamiforme.

Protórax com pilosidade predominantemente acinzentada; o topo das elevações desnudo e preto; pubescência constituída por escamas (40x). Pronoto com dois tubérculos desenvolvidos próximo ao meio; pequeno tubérculo centro-posterior e dois tubérculos pouco elevados, entre os tubérculos laterais e os dorsais; região central com pontos esparsos. Partes laterais do protórax com pontos contrastantes.

Tegumento dos élitros predominantemente avermelhado; preto nas cristas centro-basais, numa mancha dorso-central de contornos irregulares e numa mancha ante-apícal. Crista centrobasal projetada, com poucos pontos isolados no topo. Uma faixa elevada, iniciada no lado externo da crista centro-basal, oblíqua para a sutura até o meio e depois paralela à sutura até a declividade posterior, com tubérculos brilhantes no ápice e mais ou menos organizados em duas fileiras.

Profêmures robustos, fusiformes, mais escuros na base. Meso- e metafêmures enegrecidos até a metade da clava. Tíbias com pubescência escamiforme amarelo-esbranquiçada e dois anéis pretos. Tarsos com tegumento avermelhado revestidos por pubescência esbranquiçada.

Lado ventral do corpo acastanhado com pubescência esparsa branco-amarelada.

Dimensões, em mm. Comprimento total, 8,3; comprimento do protórax, 2,0; maior largura do protórax, 2,9; comprimento do élitro, 5,6; largura umeral, 3,2 .

Holótipo macho proveniente do Paraguai, Caazapá: Estero Cristal, coletado em 1-22.XI.1998 por J. Jensen (MZSP).

Discussão. Chave para distinguir as quatro espécies então conhecidas do gênero Dufauxia, foi publicada por MonNé \& MAGNo (1990) e as espécies foram reunidas em dois grupos baseados no comprimento do último urosternito. O urosternito $\mathrm{V}$ pode ser tão longo quanto os três anteriores reunidos $(D$. trichocera Monné \& Magno, 1990 e D. kourouana Lane, 1970) ou com $1 / 3$ ou $1 / 2$ do comprimento dos I-III reunidos $(D$. guaicurana Lane, 1955 e D. zikani Lane, 1970).

Em $D$. simplex sp. nov. o último urosternito é mais curto que os três primeiros, portanto, mais assemelhada com as duas últimas espécies. Distingue-se de $D$. guaicurana pelas menores dimensões; pelos tubérculos sobre a crista centro-basal nãoalinhados; pelo padrão de colorido dos élitros e pelas meso- e metatíbias dos machos sem depressão longitudinal na face posterior. Em D. guaicurana, as dimensões são menores (comprimento médio, 11,1 mm); a crista centro-basal é encimada por grânulos enfileirados; os élitros apresentam grande área dorsal de pubescência esbranquiçada (Monné \& MAGNo, l. c., fig. 2) e as meso- e metatíbias têm sulco longitudinal na face posterior.

\section{Hemilophini \\ Phoebe spegazzinii Bruch, 1908}

(Fig. 3)

Phoebe spegazzinii Bruch, 1908: 219, 1 fig.; Monné: 1995: 36 (cat.); Martins \& Galileo, 1998a: 432, fig. 8.

Esta espécie apresenta grande variabilidade nas manchas de pubescência branca, segundo pudemos constatar em exemplares procedentes do Paraguai e da Bolívia. BRUCH (1908: 220) descreveu-a de Córdoba, Argentina e figurou exemplar com padrão de manchas semelhante ao do indivíduo do Paraguai, exceto pelo pronoto que praticamente não apresenta as faixas longitudinais de pubescência branca; no exemplar da Bolívia (MZSP) o protórax é quase inteiramente branco, exceto em três faixas vermelho-acastanhadas (uma central e duas, mais curtas, nos lados). Os élitros na série sintípica e no exemplar do Paraguai são praticamente iguais, mas, no exemplar boliviano, o padrão de colorido é como aquele representado em MARTINS \& GALILEO (1998a: 432, fig. 8).

Material examinado. BOLÍVIA, Departamento ?: Rosario (L. Rocagua), macho, XI, W. M. Mann col., Mulford Biological Exploration 1921-1922 (MZSP, retido por F. Lane) (existem inúmeros topônimos com o nome Rosario). PARAGUAI, Boquerón: Loma Plata, macho, 10-22. XII. 1993, sem nome do coletor (MCNZ).

\section{Aerenicini \\ Antodice quadrimaculata sp. nov.}

(Fig. 5)

Fêmea. Cabeça com tegumento avermelhado, revestida por pubescência esbranquiçada na parte dorsal; fronte glabra e brilhante. Distância entre os lobos oculares superiores aproximadamente igual a duas fileiras de omatídios. Escapo preto dotado de pêlos abundantes. Antenômeros III-VIII amarelados com ápices pretos providos de pêlos escuros, principalmente na porção enegrecida e com comprimentos subiguais. Antenômeros IX-XI pretos, muito curtos.

Protórax com tegumento predominantemente avermelhado e com área preta mais evidente na metade anterior do pronoto. O centro do pronoto é revestido por pubescência esbranquiçada; nos lados com duas manchas longitudinais de pubescência branca compacta: uma maior, próxima da borda anterior e uma próxima da borda posterior. Proepimeros com mancha de pubescência branca compacta.

Élitros com tegumento avermelhado; uma faixa dorsal de tegumento preto da base até o meio; pubescência esbranquiçada descontínua junto da sutura no terço anterior e, mais densa, numa mancha apical. Cada élitro com três manchas de pubescência branca com- pacta: uma, pequena, na base; uma oval, maior, dorsal, oblíqua em sentido descendente da sutura para a margem; uma, arredondada, no quarto apical.

Pernas avermelhadas. Face ventral com tegumento preto, sem manchas de pubescência compacta, exceto pequena mácula no ápice do metepisterno. Urosternitos com pubescência esbranquiçada mais densa e manchas pequenas 

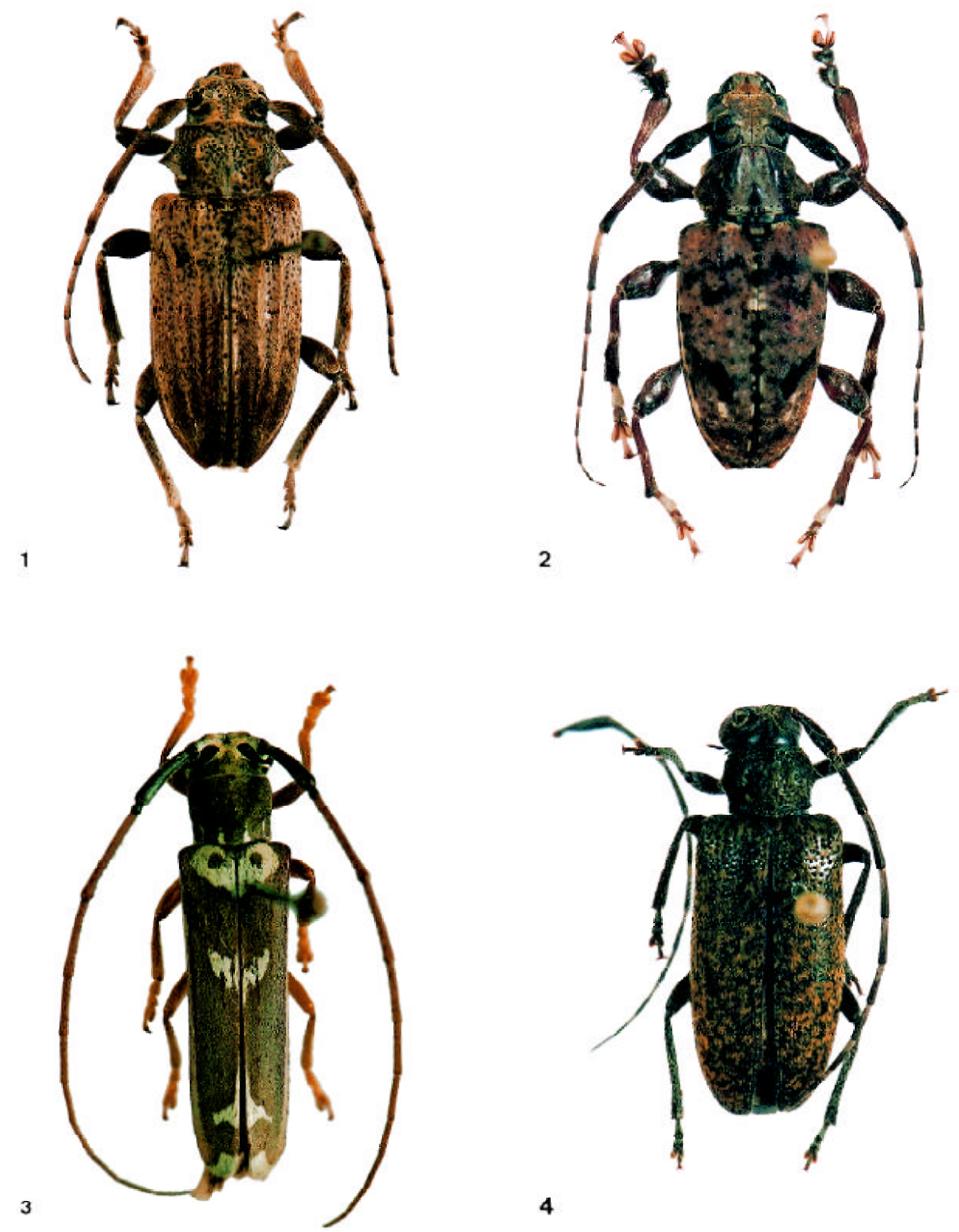

Figs. 1-4. 1, Acanthoderes (Psapharochrus) piraiuba sp. nov., holótipo fêmea, comprimento 15,3 mm; 2, Acanthoderes (A.) uyapensis sp. nov., holótipo macho, comprimento 14,7 mm; 3, Phoebe spegazzinii Bruch, 1908, macho procedente do Paraguai, comprimento 13,3 mm; 4, Drycothaea maculata sp. nov., holótipo fêmea, comprimento $14,1 \mathrm{~mm}$. 


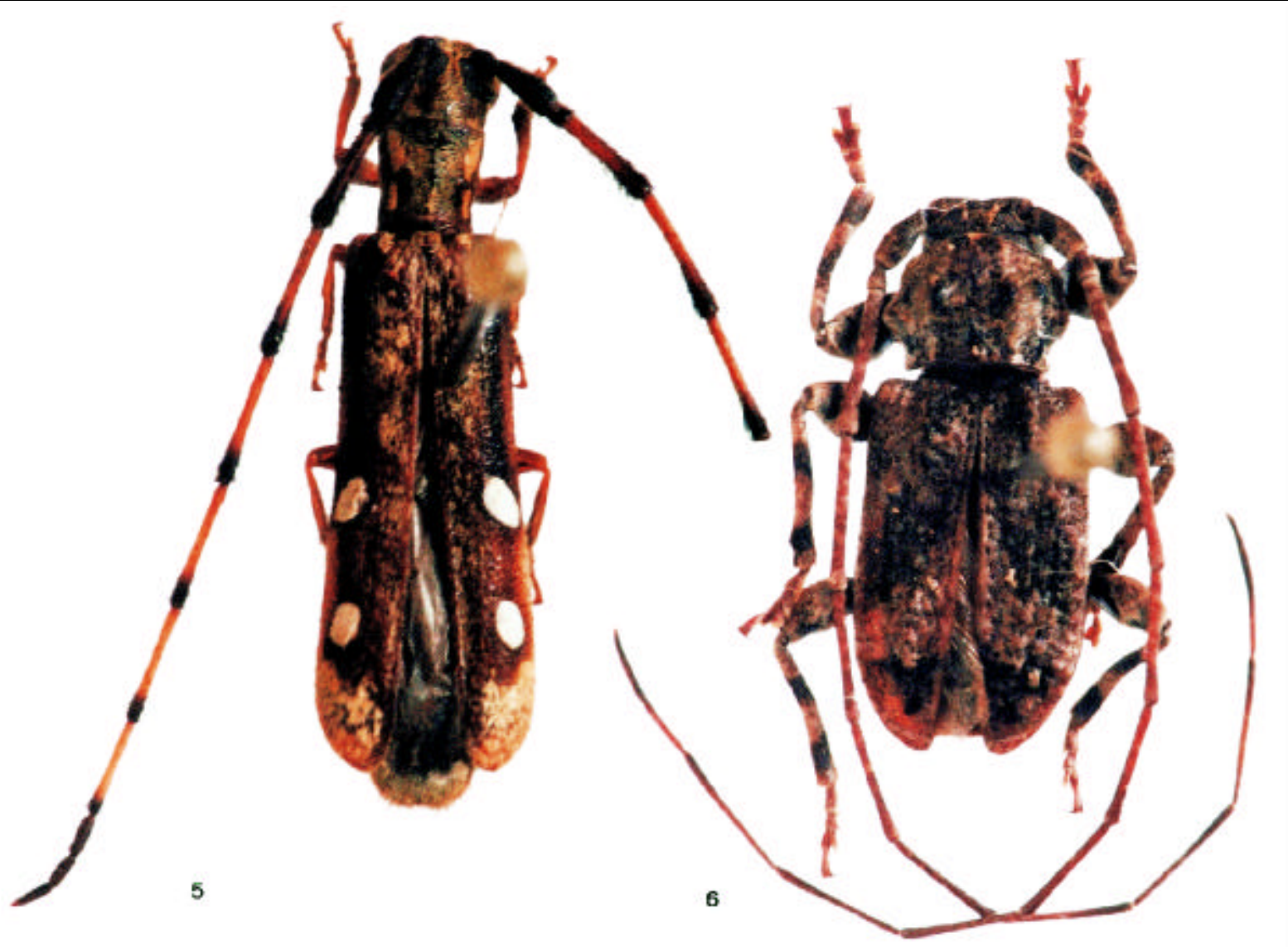

Figs. 5-6. 5, Antodice quadrimaculata sp. nov., holótipo fêmea, comprimento $10,7 \mathrm{~mm}$; 6. Dufauxia simplex sp. nov., holótipo macho, comprimento $8,3 \mathrm{~mm}$.

de pubescência esbranquiçada nos lados dos urosternitos.

Dimensões, em mm. Comprimento total, 10,7; comprimento do protórax, 1,5; maior largura do protórax (na parte anterior), 1,6; comprimento do élitro, 8,0; largura umeral, 2,3 .

Holótipo fêmea procedente do Paraguai, Caazapá: Estero Cristal, coletado em 20.XI.1999 por J. Jensen (MZSP).

Discussão. O gênero Antodice foi revisto por Martins \& GALILEO (1998b). Antodice quadrimaculata sp. nov. pertence ao grupo de espécies com flagelômeros amarelados e ápice preto. Assemelha-se a A. venustula Lane, 1973 pelo padrão de colorido elitral. Em $A$. venustula, contudo, os élitros são revestidos por pubescência esbranquiçada e só apresentam duas manchas de pubescência compacta branca. Em $A$. quadrimaculata, os élitros são avermelhados com pubescência esbranquiçada no dorso da metade anterior e junto aos ápices; além disso, apresenta três manchas de pubescência branca compacta.

\section{Calliini \\ Drycothaea maculata sp. nov.} (Fig. 4)

Fêmea. Tegumento preto. Vértice com pubescência amarelada e com duas fileiras longitudinais de pontos mais ou menos alinhados. Fronte com pontos grandes e densos. Lobos oculares superiores tão distantes entre si quanto a largura de um lobo. Escapo pontuado (32x); antenômeros III-XI com anel basal de pubescência esbranquiçada. Protórax revestido por pubescência amarelada; pontos grossos regulares e densos. Escutelo com pubescência amarelada nos lados. Élitros com pequenas áreas desnudas e revestido, na maior parte da superfície, por pubescência amarelada. Mesosterno com tubérculo. Mesepimeros lisos. Metasterno com alguns pontos contrastantes nos lados. Fêmures revestidos por pubescência esbranquiçada com evidentes pontos contrastantes. Metatíbias com pontuação áspera e dotada de pêlos curtos. Urosternitos com pubescência acinzentada e pontos contrastantes.

Dimensões em mm. Comprimento total, 14,1; comprimento do protórax, 2,4; maior largura do protórax, 3,8; comprimento do élitro, 10,5; largura umeral, 5,0.

Holótipo fêmea, procedente da BOLÍVIA, La Paz: Uyapi (Huanoy), coletado em X.1993, sem nome do coletor (MZSP).

Discussão. Drycothaea maculata sp. nov. assemelha-se a D. ochreoscutelaris (Breuning, 1940) pela pubescência elitral abundante que constitui numerosas manchas. Difere pelo tegumento preto do corpo e das pernas; pela pubescência 


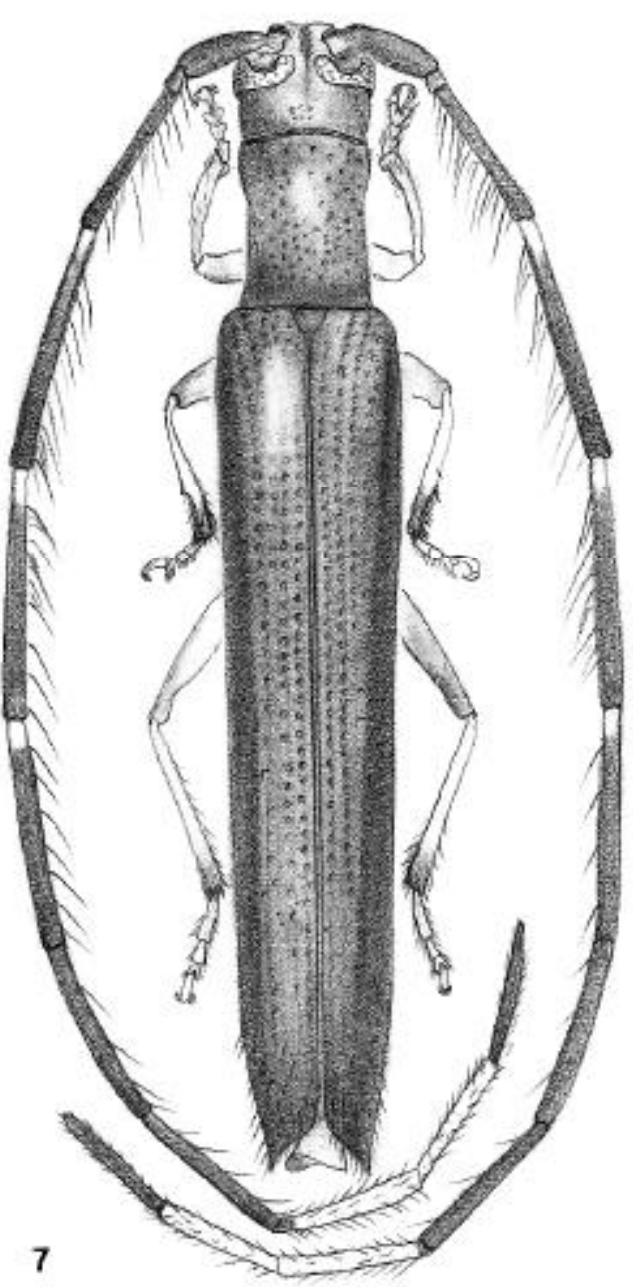

Fig. 7. Obereoides antennatus sp. nov., holótipo macho, comprimento $9,1 \mathrm{~mm}$.

corporal amarelada; pela escutelo com pubescência não fortemente contrastante; pela pubescência branca, especialmente nos antenômeros apicais, ocupando menos da metade basal; pela presença de pontos contrastantes nos fêmures. Em D. ochreoscutelaris, o tegumento do corpo e das pernas é castanho-avermelhado, a pubescência elitral é acinzentada e a do escutelo é densa e branco-amarelada; os antenômeros VII a X com cerca da metade apical escura e os fêmures não apresentam pontos contrastantes.

Falsamblesthiini

Obereoides antennatus sp. nov.

(Fig. 7)

Macho. Corpo com tegumento preto; antenômeros III-VI pretos com pequeno anel basal branco; VII-VIII e XI pretos;
IX-X inteiramente brancos; fêmures amarelados; metafêmures amarelados com pequena porção apical enegrecida; tíbias e tarsos amarelo-sujo; mesosterno alaranjado; urosternitos avermelhados no centro.

Cabeça revestida por pubescência esbranquiçada. Vértice com pontos pequenos no centro. Lobos oculares superiores tão distantes entre si quanto a largura de um lobo. Escapo sem cicatriz apical. Flagelômeros com franja de pêlos no lado interno. Antenômeros IX-X com denso revestimento de pêlos brancos (20 x). Protórax subcilíndrico, pouco mais largo junto à borda anterior. Pronoto regularmente convexo, fina e densamente pontuado. Élitros com pontos enfileirados; extremidades elitrais obliquamente truncadas com espinho externo. Face ventral com pêlos amarelados e abundantes ao longo do meio. Lados do metasterno e dos urosternitos com pontos esparsos. Último urosternito mais longo que o precedente, entalhado no ápice.

Dimensões, em mm. Comprimento total, 9,1 comprimento do protórax, 1,4; maior largura do protórax (próximo á borda anterior), 1,1; comprimento do élitro, 6,8; largura umeral, 1,4.

Holótipo macho procedente da Bolívia, La Paz: Uyapi (Huanoy), coletado em X.1993, sem nome do coletor (MCNZ).

Discussão. Obereoides antennatus sp. nov. assemelha-se a O. joergenseni (Bruch, 1911) pelo colorido corporal preto a castanho-escuro e pernas mais claras que o corpo. Distinguese pelas antenas com antenômeros III-VI com anel basal branco e IX-X inteiramente brancos e pela cor amarelo-sujo das pernas. Em $O$. joergenseni, as antenas são pretas e as pernas avermelhadas.

Agradecimentos. Ao Sr. Gerardo Arriagada (GASC) pelo envio de material para estudo e doação do material-tipo. A Antonio Santos Silva (MZSP) pela execução das fotografias.

\section{REFERÊNCIAS}

BRUCH, C. 1908. Longicórnios argentinos nuevos o poco conocidos. I. Revista del Museo de La Plata 15: 158-220.

Martins, U. R. \& M. H. M. Galileo. 1998a. Gêneros de Hemilophini (Coleoptera, Cerambycidae) semelhantes a Phoebe Audinet-Serville, 1835. Revista Brasileira de Entomologia 41(2-4): 431-437.

Martins, U. R. \& M. H. M. Galileo. 1998b. Revisão da tribo Aerenicini Lacordaire, 1872 (Coleoptera, Cerambycidae, Lamiinae). Arquivos de Zoologia 35: 1-133.

Monné, M. A. 1995. Catalogue of the Cerambycidae (Coleoptera) of the Western Hemisphere. Part XX. São Paulo, Sociedade Brasileira de Entomologia, 120 p.

Monné, M. A. \& P. R. Magno. 1990. Novas espécies de Acanthoderini neotropicais (Coleoptera, Cerambycidae, Lamiinae). Revista Brasileira de Entomologia 34: 687-691.

Tippmann, F. F. 1960. Studien über neotropische longicornier III (Coleoptera, Cerambycidae). Koleopterogische Rundschau 38: 82-817. 